\title{
Meteorological Risk Assessment in Large-scale Bridge Construction Based on Multi-source Information and Downscaling Techniques
}

\author{
HUANG Shi-cheng \\ Lab of weather and climate \\ Jiangsu Institute of Meteorological Sciences \\ Nanjing, P. R. China \\ jsimeteo@gmail.com
}

\author{
ZHOU Jia-ling \\ Lab of numerical model research \\ Jiangsu Institute of Meteorological Sciences \\ Nanjing, P. R. China
}

\begin{abstract}
This is a study to improve the pertinence and accuracy of bridge-construction meteorological risk assessment. The multi-source information including meteorological observations, the disaster information, and the meteorological conditions of construction unit were used. Taken a large-scale bridge construction in northern Jiangsu of China as an example, the paper researched the dialectical relationship between the construction weather risk and meteorological disaster risk, put forward the main evaluation indicators and evaluation methods for meteorological risk that fused multi-source information, and then established the assessment process of meteorological risk for bridge construction based on multi-source data. The results show that the meteorological factors such as temperature, wind speed, visibility and others, are the main weather risk indicators in the construction of the bridge, and high-impact weather disaster risk such as strong wind, rain and snow, frozen are important parts of the bridge construction risk. Bridge construction meteorological risk assessment base on multi-source information could be divided into three aspects: meteorological background investigation, the project site meteorological observation and analysis, and numerical model simulate. The results implied that while the risk assessment conclusions based on the former two aspects could suitable for the project purpose, the meteorological risk assessment results based on multi-source information and statistical downscaling techniques have greater reliability.
\end{abstract}

Index Terms-Construction meteorological risk, multi-source information, downscaling techniques, assessment technique process

\section{INTRODUCTION}

As a structure in the atmospheric boundary layer, the bridge construction process was mainly with open-air operations and aerial work, influenced by a variety of weather and climate system, so it has a complex construction meteorological risk. With the establishment of the bridge construction's risk management system, the meteorological risk has become one of the important contents of the system. Nevertheless, for a long time, the bridge construction meteorological risk study general carried out in a form of climate feasibility demonstration or meteorological special topic, and had not yet formed a specialized meteorological risk evaluation mechanism.

Aiming at the demands and problems of meteorological risk research in large bridge construction, and by means of integrating multi-source information, the paper studied the dialectical relationship of bridge building meteorological risk and meteorological disasters, and proposed the bridge construction meteorological risk indicators and assessment contents. Last, to provide technical basis and reference for related feasibility and risk management research, the study established a large bridge construction meteorological risk assessment processes based on multi-source information.

\section{DATA}

In this paper, the multi-source information contained meteorological observations, the disaster information, and the weather conditions of construction unit. The meteorological observations included conventional meteorological data , special meteorological data, and bridge field data; the disaster information came from disaster statistics and statistical yearbooks of meteorology and civil affairs departments; and the construction meteorological conditions , mainly derived from meteorological survey, the relevant codes and standards for bridge construction and building structures, as well as the meteorological conditions needed by the bridge construction sector.

\section{METHODOLOGY}

According to many years of experience, LIU(2006)put forward the main content of meteorological monographic study in bridge preliminary design stage, which included three aspects: (1) Climate background analysis in bridge site , (2) meteorological parameters for bridge construction, ( 3 ) meteorological research methods for bridge construction. As the monographic study focused on the meteorological windparameters such as basic wind speed, design standard wind speed, gust factor, and turbulence parameters, its contents were important meteorological support for wind-resistance of bridge engineering. Based on the technology roadmap and research 
framework for meteorological monographic study, the prototype of the bridge meteorological risk research was made up.

\section{A. Methodologies for meteorological survey}

In this paper, the meteorological survey method in bridge construction meteorological risk analysis, was based on the climatic scenario analysis in the monographic study, and had been given more contents .

In accordance with the relevant regulations, the bridge design-wind speed was the maximum 10min average wind speed of the bridge area at different return period such as 10a, 30a, 50a, or 100a. Nevertheless, in fact, there was not such a long definitive wind observation sequence in bridge site. The most important issue facing the calculation of bridge designwind speed was to build an accurate wind speed sequence that could reasonably descript the atmospheric state above ground and other different heights, which was the so-called wind speed extrapolation reconstructed problem in bridge site.

\section{B. OCN climatic trend analysis model}

Time series trend is the change of a mathematical expectation series $E(y t)$ in the total time range, the $E(y t)$ consisted of series random observations $y t$ of certain time $t$, $E(y t)=f(\beta 0, \beta 1, \ldots, t)(t=1,2, \ldots)$, in which $f(\beta 0, \beta 1, \ldots, t)$ within the scope of the study time significantly shows the tendency of rising or falling. Commonly persistent climatic trend forecasting model such as Linear Regression, Double Moving Average, Single Exponential Smoothing, Double Exponential Smoothing, Three Exponential Smoothing, could give the present value as a predictive value for the next time. Considering the time length of climatic data used in bridge construction meteorological risk analysis generally is more than 30 years, this paper applied the Optimal Climate Normal ( OCN) model to study the time trends, which was different from the continuous climatic trend analysis forecast, and used the average value of $K$ moments as predicted value of the next moment..

\section{Methodology for meteorological risk-indicator analysis}

Risk analysis is the core content of risk management. By investigating the risk analysis method in field of environmental hazards and natural disasters, the recent literature summed up five basic methods of risk analysis, including the Probability Calculation Method, Exposure Assessment, Risk Identification Method, Expected Value Calculation Method, and Experience Method (HUANG C., 2011).

In bridge construction, meteorological risk indicators are characterized by the meteorological parameters, which contain the conventional and extreme meteorological parameters. According to the mathematical reconfiguration method, if the historical climate data obtained, various meteorological risk indicators of bridge construction calculated.

In this paper, annual data, including the daily , monthly, and annual maximum observations of reference station were collected, then the maximum precipitation were calculated by $\mathrm{P}$ - III distribution or extreme I type of probability distribution.

\section{Methodology for mathematical model simulation (SDSM statistical downscaling analysis method)}

Concerning the risk assessment, it based on risk identification, applied various theories and analytical methods, then analyzed and estimated the risk's probabilities, consequences, as well as the risk size. As there are different characteristics in each kind of natural disaster risk, its corresponding risk analysis model also different, the natural disaster risk analysis is actually to find a series of functions.

At present, mathematical models in bridge meteorological research contain meteorological numerical model and climatic statistics model. Compared with the numerical model, statistical theory model has been widely applied in the field of weather risk evaluation. Fuzzy mathematical method, which based on the information diffusion theory, and the Monte Carlo method (MCM) are effective ways for numerical simulation of the bridge construction meteorological risk. MCM is nondeterministic numerical methods used to solve mathematical and physical problems, and to solve the problems approximately, it uses a series of random numbers. After finding a probability statistics analogue, it obtains the approximate solution of analogue with experimental sampling process. For an application example, the method applied to evaluate the risk of typhoon in Sutong Bridge (YANG Z., 2010).

\section{Meteorological Risk Assessment Process BASED ON MULTI-SOURCE INFORMATION}

As noted earlier, the bridge is a structure at the atmospheric boundary layer, and influenced by meteorological environment. Meteorological disasters are concrete embodiment of the reality and objective existence of the weather risk. Meteorological risk is the necessary condition of meteorological disasters, the relationship between meteorological risk and meteorological disaster is a kind of causality, the nurture process of weather risk is a quantitative changing, would eventually lead to the meteorological disasters.

Nevertheless, for a long time, the construction sector and the meteorological department had not distinguished the meteorological environment, weather risk, and meteorological disaster risk of the project construction, most of the project climatic feasibility contents were the analyses of meteorological environment. According to the requirements of bridge construction risk management, the relationship between bridge construction environment, meteorological environment, and meteorological disasters is proposed in this paper (see figure 1).

Based on previous research, this paper further put forward the large-scale bridge construction meteorological risk research method and technical process (see figure 2). The main research methods for meteorological risk on bridge construction included the meteorological survey methods, field observations, analysis methods, and numerical modeling methods. Meteorological survey is a subjective methodology for risk 
assessment and assumes a role of identifying risk factors; while the field observations and mathematical model simulation are assessment tools with more objectives in the risk quantification studies.

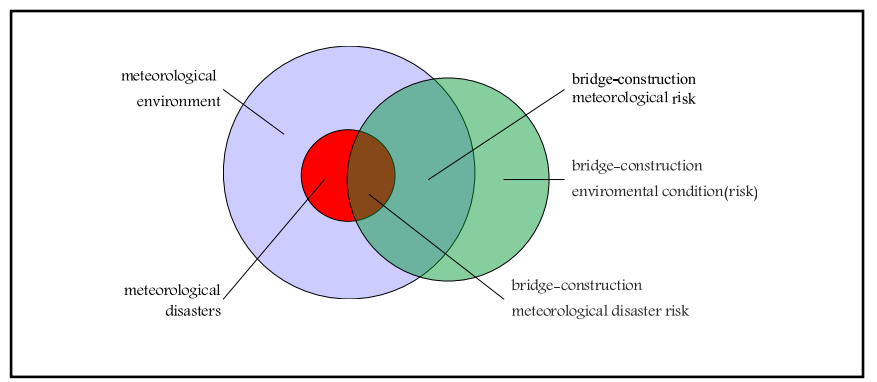

Fig. 1. Relationship between meteorological risk and meteorological disaster in bridge construction

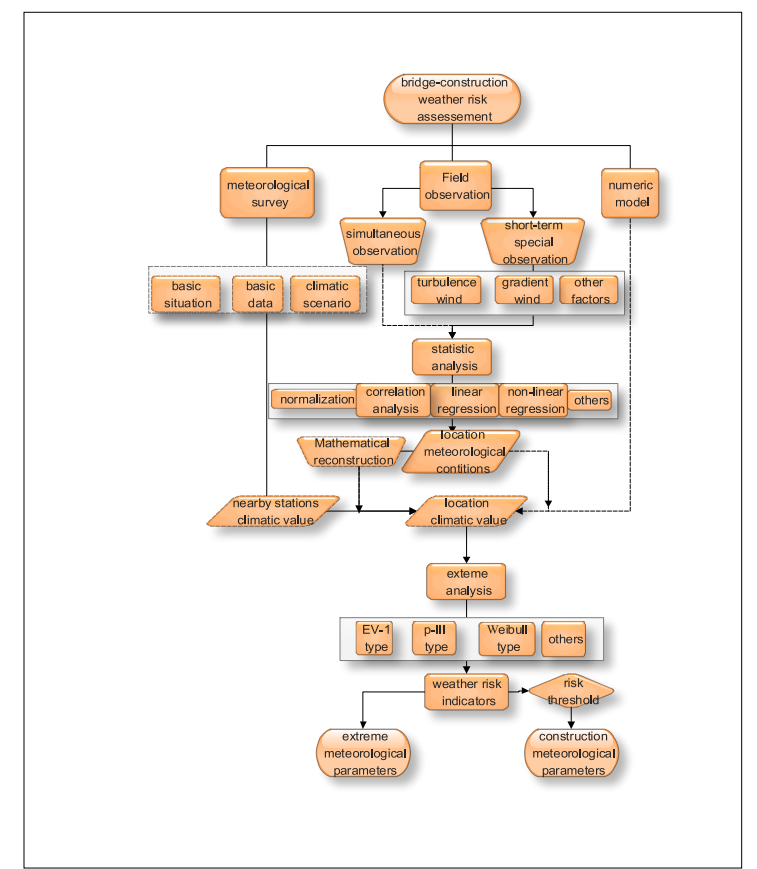

Fig. 2. meteorological risk-assessment technology process for bridge construction

\section{APPLICATION EXAMPLE}

Taken a large-scale bridge which is suited at the north of coast regional of North Jiangsu and to the south edge of the Haizhou Bay as an example, the weather-risk assessment method based on multi-source information and downscaling technology, was compared with the general evaluation method in this paper.

\section{A. General evaluation}

Analyzed the annual and monthly mean wind speed of recent 30 years of Yanweigang, Guanyun and Guannan, it can be seen from the results that the average wind speed and its trends is similar in the inland (Guanyun, Guannan). The annual average wind speed of Yanweigang is 1.8 times and 1.6 times larger than that of Guanyun and Guannan respectively.

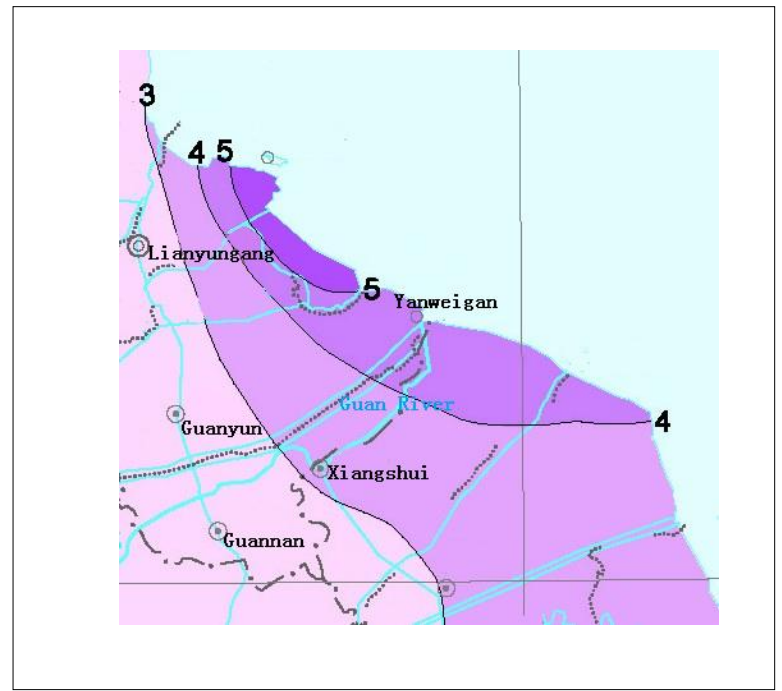

Fig. 3. Temporal and spatial distribution of average wind speed in Bridge area(unit: m/s ,Cut from "Jiangsu province climatic atlas")

According to the distribution map of annual average wind speed (Fig. 3), the region I(Yanweigang and the bridge area) belongs to a large wind-band of $4-5 \mathrm{~m} / \mathrm{s}$, while region II (the nearby weather stations such as Xiangshui) and region III(Lianyungang, Guanyun and Guannan ) belongs to the general wind-band of 3-4 m/s and small wind-band of less than $3 \mathrm{~m} / \mathrm{s}$ respectively. Obviously, it is representative to replace the bridge area historical climate data with that of Yanweigang station.

There are significant differences in average wind speed for the three stations of the bridge area, and so does the maximum wind speed. The instantaneous wind speed greater than or equal to $17.2 \mathrm{~m} / \mathrm{s}$ had appeared in bridge area, which occurred mostly in spring, secondly in summer and least in autumn. As to the annual gale days of Yanweigang, it is 4.4 times more than that of other sites. Obviously, because the bridge site is closer to Yanweigang, the design and construction of the bridge should be specially pay attention to prevent strong winds harm .

\section{B. Statistic down-scale simulation based on multi-source information}

According to the method mentioned above, this study used the MM5 model and statistical downscaling methods to simulate the bridge site and its surrounding area in more highresolution (Fig 4). In this example, January, April, July, and October represent the winter, spring, summer, and autumn respectively, the simulation results indicated that different underlying surface types such as the mountains, islands, coastal, river, and city have different wind speed distribution. The distribution map depicts a "buffer zone" of the wind change near the bridge ( $\mathrm{A}$ in the figure), which locates between the coast intensive and inland loose wind contour, so despite the 
representativeness of replacing the bridge site meteorological data with that of Yanweigang observation ,there are still differences between the actual and the reconstruction.

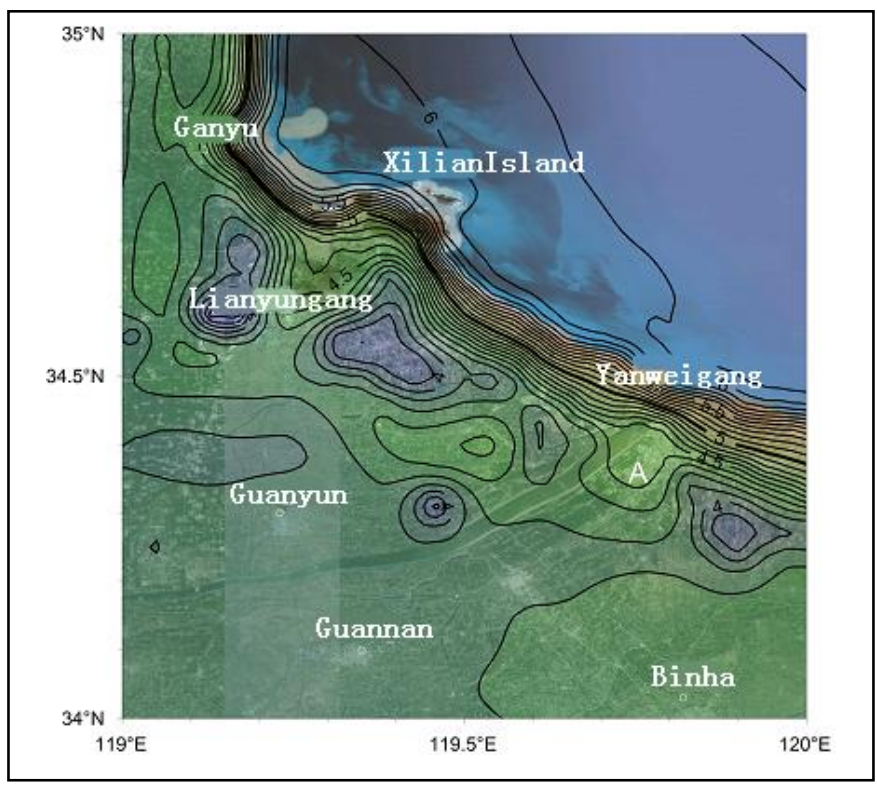

Fig. 4. Annual average wind speed simulation distribution for Guan River district

\section{CONCLUSIONS}

Based on practice of large engineering climate feasibility, this paper analyzed the relationship between meteorological risk and meteorological disasters of large bridge construction, probed into the main indicators and evaluation method of weather risk for bridge construction, and established a meteorological risk assessment processes for bridge construction. Conclusions of the study are as follows:

- 1) temperature, wind velocity, visibility are the main bridge construction meteorological risk factor, and high impact weathers such as wind, rain , snow ,freezing and so on are bridge construction meteorological disaster, which are important parts of bridge construction risk.

- 2) Based on the actual situations of geographical environment and design scheme, the process of meteorological risk assessment for bridge construction include three aspects, that is meteorological background investigation, meteorological observation analysis and numerical model simulation. Weather risk indicators of bridge construction are available in each aspect. Based on multi-source information and statistical downscaling techniques, the meteorological risk assessment results were greater reliability.

- 3) Through the meteorological elements synchronization observation between bridge site and its nearby weather stations, the annual climatic values of corresponding meteorological elements over bridge construction site can be reconstructed by the mathematical reconstruction method.
- 4) In bridge construction meteorological risk assessment, the design meteorological parameters are extreme of specific return period, including maximum temperatures, extreme minimum temperature, maximum wind speed, maximum precipitation, etc. Calculation of these parameters using Pearson Type Three distribution (P-III) and Extreme value type I distribution (EV-I) with the upper bound method, can obtain more objective calculation result.

By meteorological evaluation studies for multiple bridges, the results showed that meteorological observation in bridge project site was one of the important conditions for accurately weather risk assessment. Evaluation method based on multisource information has some advantage. In addition, the numerical modeling methods in the analysis process emerging as an assessment tool, it is differences in schema model's scale and parameters, the accuracy, rationality and reliability of the simulation of weather risk factors in bridge engineering need more verified.

\section{ACKNOWLEDGMENT}

This work was supported by grants from the Key Project of Jiangsu Province Meteorological Research Open Foundation (KZ201105) and National Natural Science Foundation of China (41175082).

\section{REFERENCES}

[1] XIANG Hai-fan, CHEN Ai-rong. "Recent advances in research on aerodynamics of extra long-span bridges,"China Civil Engineering Journal, 2003, vol. 36(4),pp. 2-8.

[2] HUANG Chong-fu, "Discussion on basic methods for risk analysis," Journal of Natural Disasters, 2011, vol. 20(5),pp. 110.

[3] LIU Cong, ZHANG Zhong-yi, HUANG Shi-cheng, "Specialized Meteorological Researches and Service on Bridge Engineering," Meteorological Science and Technology, 2004, vol. 32(6), pp. 397-403.

[4] YANG Zheng-qing, LIU Cong,YIN Yan. "Numerical experiment of the wind velocity over Sutong highway bridge." Scientia Meteorologica, 2010, vol. 30(2),pp. 193-201.

[5] LIU Yin-ge,MIAO Qi-long,GAO Qing-jiu, "The method of meteorological disaster risk assessment based on theory of information diffusion," Scientia Meteorologica Sinica, 2005, vol. 25(1), pp. 84-89.

[6] HUANG Shi-cheng,ZHOU Jialing,CHEN Ting, CHEN Bing, "Research and application of disasters evaluation methods of typhoon and gales-a case of Sutong bridge," Journal of disaster prevention and mitigation engineering, 2009, vol. 29(3), pp. 329-335

[7] Huang Shi-cheng, Chen Ting, Zhou Jia-ling, "Spatial analysis method and its application in climate feasibility demonstration of large-scale projects," Journal of meteorological and environment, 2012, vol. 28(4), pp. 90-85.

[8] Huang, Jin, Huug M. van den Dool, Anthony G. Barnston, "Long-Lead Seasonal Temperature Prediction Using Optimal Climate Normals," Climate, 1996, vol. 9, pp. 809-817. 